DEMOGRAPHIC RESEARCH

VOLUME 40, ARTICLE 47, PAGES 1375-1412

PUBLISHED 29 MAY 2019

https://www.demographic-research.org/Volumes/Vol40/47/

DOI: 10.4054/DemRes.2019.40.47

Research Article

Longitudinal employment trajectories and health in middle life: Insights from linked administrative and survey data

\title{
Carlo Devillanova
}

\section{Michele Raitano}

\section{Emanuela Struffolino}

(C) 2019 Devillanova, Raitano \& Struffolino.

This open-access work is published under the terms of the Creative Commons Attribution 3.0 Germany (CC BY 3.0 DE), which permits use, reproduction, and distribution in any medium, provided the original author(s) and source are given credit.

See https://creativecommons.org/licenses/by/3.0/de/legalcode. 


\section{Contents}

1 Introduction 1376

$2 \quad$ Background and recent findings 1377

3 Hypotheses 1380

$4 \quad$ Data and methods $\quad 1381$

4.1 Data 1381

$\begin{array}{lll}4.2 & \text { Self-reported health } & 1382\end{array}$

4.3 Employment trajectories as sequences of states 1382

$\begin{array}{lll}4.4 & \text { Multivariate analyses } & 1384\end{array}$

$5 \quad$ Results 1385

$5.1 \quad$ Longitudinal employment trajectories 1385

5.2 Longitudinal employment trajectories and health 1388

5.3 Additional remarks on the issue of reverse causality 1393

6 Conclusions 1393

$\begin{array}{ll}\text { References } & 1396\end{array}$

$\begin{array}{ll}\text { Appendix } & 1405\end{array}$ 


\title{
Longitudinal employment trajectories and health in middle life: Insights from linked administrative and survey data
}

\author{
Carlo Devillanova ${ }^{1}$ \\ Michele Raitano ${ }^{2}$ \\ Emanuela Struffolino ${ }^{3}$
}

\begin{abstract}
BACKGROUND

The paper adopts a long-term perspective in analysing the association between health and employment histories, often characterized by substantial mobility over time across multiple statuses and contractual arrangements. The available evidence is largely based on static or short-run dynamic approaches and only compares across few employment statuses.
\end{abstract}

\section{OBJECTIVE}

We investigate how different longitudinal employment trajectories defined over multiple yearly labour market states are associated with self-reported health in middle life.

\section{METHODS}

We use a unique dataset linking the Italian component of the EU-SILC cross-sectional samples (2004-2012) with individuals' complete working histories from the National Social Security registers. We apply sequence and cluster analysis to reconstruct individual working histories between the ages of 15 and 45 and to identify typical trajectories. We then estimate the association between employment trajectory and selfreported health at age 45 .

\section{RESULTS}

Trajectories characterized by intermittent working episodes and long periods of unemployment or inactivity are associated with worse health at age 45. Long-term exposure to blue-collar jobs (potentially physically demanding, more vulnerable to

\footnotetext{
${ }^{1}$ Università Commerciale Luigi Bocconi, Milan, Italy.

${ }^{2}$ Università degli Studi di Roma La Sapienza, Rome, Italy.

${ }^{3}$ Wissenschaftszentrum Berlin für Sozialforschung, Berlin, Germany. Email: emanuela.struffolino@wzb.eu.
} 
work accidents, and allowing for low levels of individual control) operates similarly to persisting/intermittent joblessness in terms of health outcomes.

\section{CONTRIBUTION}

Unlike 'point-in-time' approaches, our sequence analysis application provides unique insights into the fact that the association between the configuration of complete trajectories as they unfold over time and health in middle life are significant and substantive over and above the time spent in specific labour market arrangements (e.g., unemployment) and type of occupation (e.g., blue collar).

\section{Introduction}

A vast literature shows that health is unevenly distributed across social groups (Friel and Marmot 2011; Marmot 2015), noting the association between employment status and individual health and wellbeing (Benach and Muntaner 2013; Cai 2010). In fact, socioeconomic status, indexed by occupational position, is one of the strongest predictors of morbidity and premature mortality (Stringhini et al. 2017).

However, two calls for additional research emerge clearly from the literature reviewed in the next section. First, the relationship between labour market experiences and health should consider a large spectrum of employment statuses in order to capture the wide range of conditions that characterize contemporary labour markets (Benach and Muntaner 2007). Second, the issue should be addressed by looking at long-run employment trajectories over the life course, given that, first, most mechanisms linking employment statuses and individuals' health outcomes depend on the length of exposure to a specific status and require time to show up, and, second, short-term labour market events can have long-lasting effects over the entire employment career (Benach et al. 2016). Both recommendations highlight two major weaknesses of the existing research, which generally focuses on a small number of employment statuses at one or a few points in time. As a consequence, the factual exposure to different positions is overlooked, and this might explain the mixed research results (Waenerlund et al. 2014).

We empirically contribute to this literature by assessing the association between individuals' longitudinal employment trajectories, defined over multiple yearly labour market states, and self-reported health (henceforth SRH) in middle life. We use a unique dataset that links administrative records of complete individual working histories from age 15 to age 45 and survey data (the 2004-2012 waves of the Italian component of the EU-SILC). We can therefore reconstruct 31-year-long trajectories across which each year is defined by one of the 11 mutually exclusive employment 
statuses available in the data. We use the sequence analysis framework (Abbott 1995; Aisenbrey and Fasang 2010) to identify a typology of employment trajectories and inquire how the latter are associated with differentials in individuals' SRH at age 45 .

Compared with traditional cross-sectional analyses and short-run dynamic approaches that look at single transitions between states, sequence analysis allows us to capture processes as they unfold over time: we therefore conceptualize the mobility across multiple employment statuses as building blocks of whole longitudinal working histories. Indeed, we document that the association between employment and health using short-term labour market states - as is standard in the literature when focussing on 'point-in-time' outcomes - is extremely sensitive to the age at which employment statuses are recorded and to their aggregation, strengthening the rationale for using sequence analysis. A further advantage of exploiting long-run trajectories is that they reduce the concerns of possible reverse causality between employment and health. We later argue that, in the context under study and given the sample selection, reverse causality is unlikely to drive our results. Nonetheless, our inability to directly address this issue with the available data suggests a need for caution in any causal interpretation of the parameters of interest.

We find that being out of the regular labour force due to long-term unemployment (or undeclared jobs) and experiencing job insecurity due to frequent short unemployment spells correlate significantly with worse health. Among those with a stronger attachment to the labour market, blue-collar workers report significantly poorer health compared to professionals, white-collar workers, and public sector employees, whereas differences between blue-collar workers and those experiencing frequent job insecurity are not significant. The size of the estimated effect is large: for instance, the probability of a public sector employee reporting good or very good health instead of bad or very bad health is almost twice of that for blue-collar workers.

\section{Background and recent findings}

Many studies address the effects on health of individuals' experiences in the labour market, captured by, e.g., unemployment spells (Strully 2009), socioeconomic occupational position (Stringhini et al. 2017), and employment quality (Van Aerden et al. 2016).

The literature has identified various possible channels through which experiencing careers characterized by unemployment or specific employment statuses is expected to be associated with health differentials. When unemployment is concerned, income deprivation linked to periods of joblessness reduces individuals' capacity to access medical care and to afford a healthy dwelling and food, thus directly compromising 
health. Unemployment might also trigger a loss of social status and self-fulfilment (Jahoda 1982) as well as harmful behaviours (Laitinen, Ek, and Sovio 2002). In accordance with these theoretical predictions, empirical studies find a negative association between periods spent in unemployment and self-rated physical health and psychological wellbeing (Drydakis 2015; Huber, Lechner, and Wunsch 2011; Schaller and Huff Stevens 2015; Strully 2009). These findings are consistent with those based on more objective measures of health (Michaud, Crimmins, and Hurd 2016; Ardito et al. 2017) and mortality (Sullivan and Von Wachter 2009).

Exiting the labour market is also associated with less physical activity (Grayson 1993) and health-risk behaviours (Fagan et al. 2007; Mossakowski 2008; Schunck and Rogge 2010). In the long run, youth unemployment has scarring effects on mental health (Strandh et al. 2014) and mortality (Sullivan and Von Wachter 2009). These results are robust to different identification strategies - layoffs as an exogenous source of job loss (Sullivan and Von Wachter 2009; Strully 2009), matching methods (Ardito et al. 2017), or instrumenting for job loss (Farré, Fasani, and Mueller 2018).

Most studies, however, conceptualize labour market participation dichotomously, and estimate the effects on health of experiencing unemployment versus being in employment. This perspective overlooks a highly relevant aspect of the employmenthealth association, as it obscures the large heterogeneity of effects on health across socioeconomic occupational positions. In fact, workers' exposure to professional diseases (Baxter et al. 2010), work accidents, and job insecurity varies according to their different occupations and contractual arrangements. Jobs that allow for more (sense of) control and more creativity are associated with better health and higher levels of well-being (Mirowsky and Ross 2007; Ross and Wu 1995). Additionally, these occupations are less physically demanding, so that professional/white-collar/creative workers are less exposed to factors that operate as proximate determinants of mortality, as compared, for example, to blue-collar workers (Moore and Hayward 1990).

A growing number of studies address the health consequences of employment quality, with a focus on non-standard forms of employment (henceforth NSE), a concept that encompasses several dimensions of the employment relationship that distinguishes it from the permanent, full-time employment benchmark. The contemporary debate links NSE and precarious employment (Pirani 2017), stressing their association with the erosion of working conditions in terms of job control, asymmetric power relationships, prospects of promotion, and remuneration (Godin and Kittel 2004); increase in unplanned working hours (Costa, Sartori, and Åkerstedt 2006); higher perceived employment insecurity (Griep et al. 2016); less training and access to safety equipment (Quinlan 2015); and higher injury rates and lower labour standards (Benach et al. 2014). 
Evidence indicates a negative association between NSE and health problems, SRH, and psychological distress (Griep et al. 2016; Benach et al. 2014; Cottini and Lucifora 2013; Quesnel-Vallée, DeHaney, and Ciampi 2010; Robone, Jones, and Rice 2011), although the findings suggest a broad heterogeneity of these effects across contexts (Bardasi and Francesconi 2004; László et al. 2010; Gash and McGinnity 2006; Rodriguez 2002). As in the case of unemployment, the negative health gap of NSE has been shown to result from the causal effect of employment conditions on health (Cottini and Lucifora 2013; Ehlert and Schaffner 2011; Kim et al. 2012; Moscone, Tosetti, and Vittadini 2016; Pirani and Salvini 2015; Quesnel-Vallée, DeHaney, and Ciampi 2010). A negative health gradient characterizes undeclared work and the informal sector (Benach and Muntaner 2013; Quinlan 2015). However, studies on the association between NSE and health often also rely on comparison across a few employment statuses rather that the full spectrum of work arrangements (Quinlan 2015). Studies that cover the multidimensionality of NSE and precarious employment are an exception (Lewchuk, Clarke, and de Wolf 2011; Quinlan and Bohle 2004; Scott-Marshall and Tompa 2011; Silla, Gracia, and Peiró 2005; Vives et al. 2015).

A second somehow disregarded aspect in the literature concerns the narrow focus on the health effects of short periods of exposure to (or single transitions across) specific labour-market statuses. Even studies that assess the long-term consequences of unemployment often focus on single experiences of unemployment (Tapia Granados et al. 2014; Sullivan and Von Wachter 2009) or a few unemployment spells (Strandh et al. 2014), although a longer period of exposure - seven years - has been recently considered (Ardito et al. 2017). A similar concern applies to the literature on NSE, where only a few studies use a longitudinal perspective, often limited to a few years of observation (Cottini and Lucifora 2013; Drydakis 2015; Ehlert and Schaffner 2011; Pirani and Salvini 2015; Sarti and Zella 2016; Virtanen et al. 2004, 2005).

However, the relationship between employment status and health conditions is intrinsically dynamic, as the effect of unemployment and job attributes on health outcomes depends on the length of exposure and requires time to appear. Furthermore, the exposure itself might depend on short-run labour market episodes that could have long-lasting consequences on individual careers. For example, unemployment experiences can have scarring effects on individual labour-market careers (Arulampalam 2001; Gangl 2004; Gregg and Tominey 2005). On the contrary, NSE might facilitate work-family reconciliation, the inclusion of the unemployed or informal sector employees in the official labour market, or a transition toward a stable occupation (Cockx and Picchio 2012; Booth, Francesconi, and Frank 2002; Tompson and Price 2009). Clearly, temporary employment arrangements will produce very different health outcomes if they are stepping-stones to a more advantageous labour market status, or if they result in occupational instability. 
In summary, a truthful understanding of the issue requires a long-run perspective and therefore analytical strategies that encompass employment trajectories over the life course to unveil the long-lasting effects of labour market statuses. Sarti and Zella (2016) and Waenerlund and colleagues (2014) study the association between employment trajectories and health, using, respectively, five/four mutually exclusive employment statuses over four/twelve years. They find that the group with the least labour market attachment has the worst health status (Waenerlund et al. 2014) and that transition from a stable job position to inactivity or unemployment is associated with a higher probability of reporting worse health conditions (Sarti and Zella 2016). However, in these studies the observational window remains relatively short and the range of employment statuses is limited. We complement this research by considering a longer portion of individuals' life courses and a richer variety of employment statuses.

\section{Hypotheses}

Previous literature suggests that long-term unemployment and frequent short unemployment spells correlate significantly with worse health. For those in employment, a long-term career in low occupational positions and manual occupations is characterized by a negative health gradient, with undeclared work in the informal sector expected to deliver the worst health results. Although in our empirical investigation we are able to characterize a relatively large spectrum of mutually exclusive employment statuses, data constraints prevent distinguishing between longterm unemployment and undeclared jobs; nor can we precisely identify the quality of the employment relationship (see next section). However, we can reasonably assume that blue-collar workers are disproportionately employed in manual occupations, characterized by lower employment quality (e.g., less sense of control) and more exposure to work accidents and professional diseases. On the other end of the spectrum, professional/white-collar and public employees are likely to be less exposed to health risks and to experience less job instability. Admittedly, large heterogeneity is expected within the employment statuses identified in our analysis, in terms, e.g., of socioeconomic position or quality of the employment relationship (Stringhini et al. 2017; Van Aerden et al. 2016). This heterogeneity could induce an attenuation bias, which would increase the likelihood of finding no association between employment trajectories and health. We summarize these observations in the form of two testable predictions: 
Hypothesis 1: Being out of the regular labour force due to long-term unemployment (or undeclared jobs) and experiencing job insecurity resulting from frequent short unemployment spells correlate with worse health.

Hypothesis 2: Long exposure to blue-collar jobs is associated with worse health conditions.

\section{Data and methods}

\subsection{Data}

Our analysis uses AD-SILC, a longitudinal dataset that merges nine cross-sectional waves (2004-2012) of the IT-SILC survey (the Italian component of the European Union Statistics on Income and Living Conditions - EU-SILC - carried out by the Italian National Statistical Institute - ISTAT) with administrative data from the Italian National Social Security Institute (INPS). The INPS linked the two datasets using a unique individual identifier (fiscal code), which was then removed for privacy reasons. Therefore, the AD-SILC dataset contains all variables from the cross-sectional waves of the IT-SILC and each individual's entire working history from INPS register data.

We select individuals who were 45 years old in any wave of the IT-SILC, and we retrospectively follow their employment histories for a 31-year-long period, i.e., from age 15 to age 45 . The interviewees were 45 years old in different IT-SILC waves (2004-2012). Hence, our sample contains individuals belonging to nine birth cohorts (1960-1968), whose 31-year-long employment trajectories unfold over different periods (1974-2004 for those interviewed in 2004; 1982-2012 for those interviewed in 2012). Therefore, the cohort effect is controlled for in the regression analysis. We cannot further extend the observation period because information on type of working activity is incomplete before 1974 .

We exclude from the sample immigrants (i.e., non-Italian citizens), for whom we cannot observe employment trajectories before their arrival in Italy. We further exclude disabled individuals (identified by the INPS as disability-benefit recipients) and interviewees who declared in the IT-SILC survey that they had never worked during their life. The former sample selection rule should further reduce concerns regarding possible reverse causality between labour market experience and health. The final sample is composed of 2,313 individuals. 


\subsection{Self-reported health}

The dependent variable is SRH measured at the year of interview, as reported in the ITSILC dataset. SRH is operationalized by a question asking to self-rate own general health using one out of five possible categories: very good, good, fair, bad, or very bad. Admittedly, self-reported measures of either general health or specific illnesses may be subject to measurement errors due to interpersonal differences in the way such assessments are perceived (Bago d'Uva et al. 2008; Sen 2002; Baker, Stabile, and Deri 2004). However, SRH has been shown to have good predictive power for future mortality and morbidity (Ringback Weitoft 2005) and is a unique, valuable indicator of more detailed measures of health status (Bailis, Segall, and Chipperfield 2003; Jylhä 2009). In fact, SRH is a commonly studied outcome in this research field (Bardasi and Francesconi 2004; Drydakis 2015; Ehlert and Schaffner 2011; Kim et al. 2012; Ferrie et al. 2005; Virtanen et al. 2005; Waenerlund et al. 2014) and the only one that has been addressed in large quantitative studies on Italy (Carrieri et al. 2014; Ehlert and Schaffner 2011; Pirani 2017; Pirani and Salvini 2015; Sarti and Zella 2016).

\subsection{Employment trajectories as sequences of states}

To identify a typology of employment trajectories we rely on the methodological framework of sequence analysis, which considers social processes as sequences of qualitative categorical states (Abbott 1990, 1995). ${ }^{4}$ Sequence analysis emphasizes the importance of studying processes in their temporal unfolding: entire trajectories are understood in their continuity over time (Aisenbrey and Fasang 2010), rather than being analysed in terms of the probability of the occurrence of certain events or the timing of single transitions between states. For this reason, sequence analysis has been widely adopted in both demography and life-course research to analyse family/employment trajectories (e.g., Elzinga and Liefbroer 2007; Aassve, Billari, and Piccarreta 2007), as well as differences in later outcomes as a function of such trajectories (e.g., Mariani, Özcan, and Goisis 2017). Typical trajectories are identified by applying cluster analysis to group sequences representing individual realizations of the process under study: the final aim is to uncover typologies based on regularities in timing, duration, or sequencing of states along sequences.

We reconstruct sequences of employment statuses for individuals in our sample, whose working histories are observed from age 15 to 45 . The INPS component of the AD-SILC dataset allows us to reconstruct reliable individual employment trajectories

\footnotetext{
${ }^{4}$ Sequence analysis is performed using the software R version 3.2.5 (R Core Team 2016) and the R packages TraMinerR and TraMineRextras (Gabadinho et al. 2011; Ritschard et al. 2013).
} 
starting from the first labour market episode. The INPS archives are attrition-free and cover all individuals lawfully working in Italy. The archives report for each individual, on a yearly basis, the number of weeks worked (including sickness or parental leave allowances and temporary suspension, without firing, covered by the so-called Cassa Integrazione allowance) and the employees' occupation (blue-collar or white-collar worker). INPS archives also contain information on whether working arrangements are full-time or part-time, as well as the prevalent type of working relationship in a year, classified into five employment categories: public and private employees, freelance professionals (e.g., architects, lawyers), self-employed (i.e., craftsmen, shopkeepers, and self-employed farmers), and parasubordinate workers (i.e., bogus self-employed workers, who work formally according to a nonsubordinate arrangement, but work de facto as if they were dependent employees with reduced welfare state guarantees).

Unfortunately, the INPS only started to record information on contract duration for employees (open-ended or fixed-term) in 1998, so we could not include this distinction in our analysis (note, however, that the share of temporary employees in the total number of employees was low in Italy until the end of the 1980s; approximately 5\% according to Eurostat). ${ }^{5}$ Due to data limitation, we could not further distinguish between type of occupation and working-hour arrangements within the public sector. Note, however, that in the public sector almost all employees are white-collar workers and part-time arrangements are voluntary in most cases. Finally, note that the INPS archives do not record whether non-working individuals are actively searching for a job, so that 'long-term unemployment' gathers together inactivity spells, long-term unemployment, and, possibly, informal work in general (including home-based informal work).

Finally, the IT-SILC component allows us to measure the time spent in education. Individuals are considered in education from age 15 until they attain their highest degree (the year when the highest level of education was attained is recorded in the EUSILC). This specific aspect is especially valuable because of the well-established educational gradient in health status, morbidity, and mortality (Carroll et al. 2017): for Italy, no other available data source based on INPS registers contains information on workers' education, so this feature makes the AD-SILC particularly suitable for studying differential health outcomes.

To sum up, by using the AD-SILC dataset we can observe a relatively large spectrum of employment statuses that might be experienced during each year of labour market participation. We consider 11 mutually exclusive statuses: four employment categories (public employees, freelance professionals, self-employed, and parasubordinate workers), four different types of employees in the private sector (white-collar full-time; blue-collar full-time; white-collar part-time; blue-collar part-

\footnotetext{
${ }^{5}$ For an overview of the recent dynamics of the Italian labour market, see Mussida and Lucarelli (2014).
} 
time), education, short-term unemployment (having worked less than 26 weeks during the year), and long-term unemployment (having never worked during a year).

As an example, we show the distribution of employment statuses for individuals aged 45 at the date of the survey (see Figure A-1 in the Appendix): $55.7 \%$ of them were employed in the public or the private sector, a relatively high share $(18.1 \%)$ worked through nonsubordinate arrangements (professionals, parasubordinates, or selfemployed), while $9.2 \%$ of the sample was unemployed for at least 6 months during the year and $17.0 \%$ never worked (or were undeclared workers) in the year.

The clustering procedure of sequences of employment statuses involves, first, the computation of a pairwise dissimilarity matrix based on a distance measure between sequences. Because the duration of the spells is of primary importance when evaluating the salient dimensions of working trajectories such as stability, we used the Longest Common Subsequence metric - LCS (Bergroth, Hakonen, and Raita 2000) - which is particularly sensitive to differences in the relative length of continuous exposure to the same state (Studer and Ritschard 2016).

The pairwise dissimilarity matrix is the input for a cluster analysis that uses the partitioning around medoids criteria - PAM (Kaufman and Rousseeuw 2005) - to group similar sequences. The medoids are sequences showing the smallest dissimilarity to the other sequences in the cluster to which they belong, so the cluster solution expresses maximal sequence internal homogeneity and external heterogeneity (the PAM algorithm pursues a global optimization: by contrast, hierarchical methods usually follow a local optimization that is not optimal at the global level). A sevencluster solution was identified as optimal according to the average silhouette width (0.4), which measures the coherence of the assignment of each sequence to a cluster. ${ }^{6}$

The results (available upon request) of robustness checks for the clustering step, using different distance metrics that maximize sensitivity to continuous exposure to the same state, were highly consistent in terms of qualitative differences between the clusters and in terms of cluster assignment. ${ }^{7}$

\subsection{Multivariate analyses}

We analysed the association between clusters of employment trajectories and the categorical-ordered SRH. We estimated ordered probit models for the probability of reporting very good $(13.1 \%)$, good $(62.2 \%)$, fair $(21.2 \%)$, bad $(2.7 \%)$, and very bad

\footnotetext{
${ }^{6}$ The seven-cluster solution is supported by additional cut-off criteria, such as the Point Biserial Correlation and Hubert's Gamma criteria (values 0.71 and 0.97 respectively).

${ }^{7}$ Specifically, we tested optimal matching with different insertion and deletion costs, as well as optimal matching between sequences of spells. The robustness checks suggested that LCS is preferable.
} 
$(0.8 \%)$ health at age 45 . Note that an overwhelming majority of individuals report at least fair general health, while $3.5 \%$ of individuals rate their health as bad or very bad. ${ }^{8}$ This is explainable, given the relatively young age of individuals in our sample. All regressions include controls for gender (men 52.8\%), marital status (single never married 16.7\%; married $73.8 \%$; separated/divorced/widow 9.5\%) and year of birth dummies (1961-1968). Note that education is not included in the basic covariates because it is one of the states that are used to code each time point across the employment trajectories.

As a robustness check (shown in the Appendix, Table A-2 and Table A-3), we further controlled for several individual characteristics that are endogenous to the type of employment trajectory: highest educational level attained (lower secondary $43.4 \%$; upper secondary $43.8 \%$; tertiary $12.8 \%$ ); total number of transitions across employment states (mean 5.5, standard deviation 3.2); transitions toward long-term and short-term unemployment spells (respectively: mean 1.5, s.d. 1.3; mean 1.4, s.d. 1.3); the number of years with an unemployment spell that lasted more than 25 weeks (mean 9.8, s.d. $8.9) ;{ }^{9}$ the (logged) equivalized disposable income of the individual (mean 9.75, s.d. 1) and of his/her household members (mean 7.79, s.d. 3.97); household capacity to face unexpected expenses (yes/no); and ability to make ends meet (with great difficulty, with difficulty, with some difficulty, fairly easily, easily, very easily).

\section{Results}

\subsection{Longitudinal employment trajectories}

Figure 1 shows the 7-cluster solution for individuals' employment trajectories from age 15 to age 45 , coded according to the 11 yearly possible employment statuses. Each plot of Figure 1 displays 50 representative trajectories for individuals belonging to the clusters, ordered by timing of end of education (Fasang and Liao 2014) ${ }^{10}$ : the

\footnotetext{
${ }^{8}$ The BIC test for the parallel lines assumption confirms our choice of the ordered probit model (Williams 2006).

${ }^{9}$ Controlling for the duration of unemployment during a year allows us to better capture short-term unemployment periods that might, however, have long-lasting scarring effects on SRH.

${ }^{10}$ The relative frequency sequence index plots in Figure 2 are generated for each cluster by (1) sorting sequences using multidimensional scaling, (2) dividing the sample into 100 subgroups, (3) choosing one medoid sequence per subgroup as a representative sequence, and 4) plotting the medoid sequences. The original seqplot.rf function implemented in the $\mathrm{R}$ package TraMineRextras was edited by Emanuela Struffolino. The representation quality by cluster is displayed in Figure A-2 in the Appendix, in which a boxand-whisker plot represents dissimilarity with the medoid within each frequency group. Additionally, the state distribution plots for the clusters of employment trajectories are presented in Figure A-3 in the Appendix.
} 
percentages next to the clusters' names indicate the share of individuals from the initial sample allocated to each cluster representing a 'model' of longitudinal labour market participation.

\section{Figure 1: Clusters of employment trajectories from age 15 to age 45}
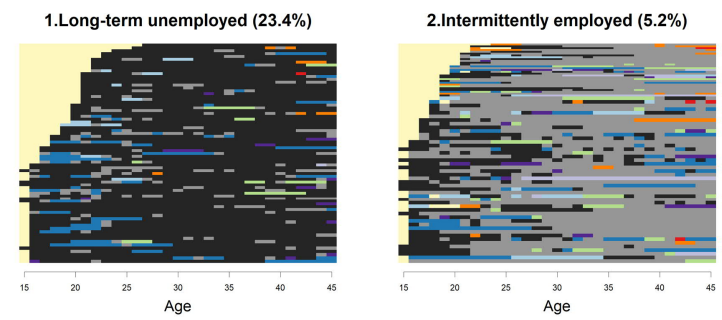

3.Self-employed (12.2\%)

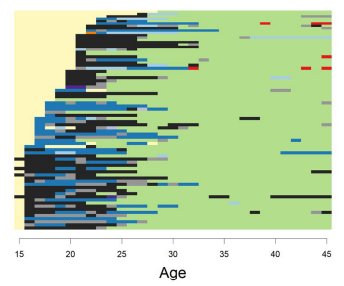

4.Professional (6.1\%)

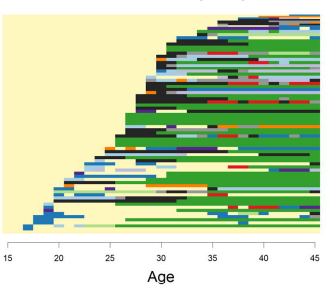

5.Public employee (15\%)

6.Blue-collar worker $(21.5 \%)$
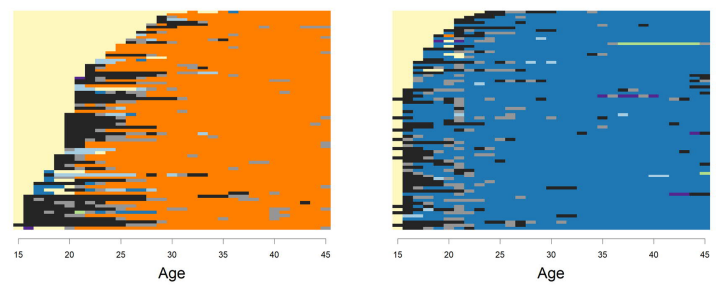

7.White-collar worker (16.7\%)
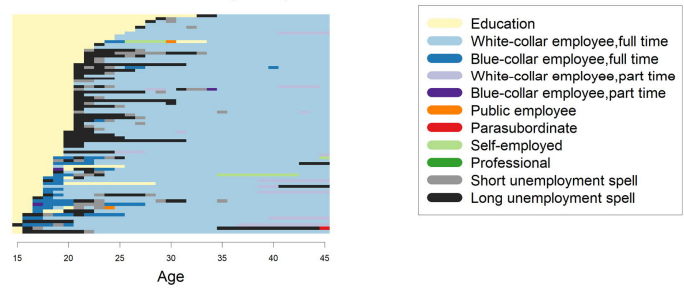

Note: For each cluster, 50 representative sequences are shown, ordered by timing of the end of education. The assessment of the representativeness can be found in Figure A-2 in the Appendix. The state distribution plots displaying the share of individuals in each cluster in a specific state at each point in time are shown in Figure A-3 in the Appendix. Source: Elaboration of AD-SILC data. 
The seven clusters of employment trajectories are characterized by the prevalence of one state, but the graphical representation highlights the complexity of individual pathways, indicated by the presence of multiple transitions between different states for the great majority of the workers in the sample. Cluster (1) 'long-term unemployed' is mostly populated by individuals who spent several years out of formal work (23.4\%), while 'intermittently employed' workers in cluster (2) (5.2\%) experienced frequent episodes of short unemployment (less than 26 weeks in a year) in between either longterm unemployment or short employment episodes in different occupations. Cluster (3) gathers workers who stabilized as 'self-employed' between approximately ages 21 and 26, after having passed through either unemployment or blue-collar employment posteducation (12.2\%). A longer time-span in education followed by (mostly) 'professional' occupations characterizes cluster (4) (6.1\%). In cluster (5) employees stabilize as 'public employees', mostly after education or a few years of long-term unemployment $(15 \%)$.

The common feature of the trajectories of individuals in cluster (6) is a direct and early transition from education to blue-collar employment in the private sector (21.5\%). Finally, cluster (7) identifies the very stable long-term pathways of white-collar workers in the private sector $(16.7 \%)$. As noted above, the sequence of the long-term unemployed might include heterogeneous situations: (1) long-term unemployed; (2) inactive; and (3) informal sector worker. According to the review in Quinlan (2015), the long-term unemployed and informal workers should be characterized by the worst health outcome.

As expected, the cluster distribution differs by gender (Table 1, column percentages), with women having on the one hand a higher incidence of long-term unemployment, possibly associated with home-based informal work, and on the other hand being more likely to be employed in the public sector. By contrast, men are more likely to be self-employed or blue-collar workers.

Table 1 also shows the distribution of employment status at age 45 reported in the IT-SILC survey by cluster of employment trajectory. The results confirm the heterogeneity of the 'long-term unemployed' cluster: $54.5 \%$ of individuals belonging to this cluster self-define themselves as employed (full-time or part-time) and $28.9 \%$ as inactive. The share of self-reported inactivity at age 45 is lower than $10 \%$ in the other clusters of employment trajectories. Below we present regression results with and without individuals who self-report as inactive at age 45 in the IT-SILC sample. Note also the high shares of part-timers in the clusters 'long-term unemployed' $(12.8 \%)$, 'intermittently employed' (15.7\%), and 'white-collar workers' (15.8\%): it is plausible that part-time is an individual choice only in the latter case, while in the former cases, involuntarily part-time should represent a form of NSE associated with poor working conditions. 
Table 1: Sample distribution of individuals in the clusters by gender (column percentages) and self-defined employment status at the end of the trajectory (row percentages)

\begin{tabular}{lrrrrrrr}
\hline & & Gender & \multicolumn{4}{c}{ Self-defined status in IT-SILC at age 45 } \\
Cluster & Men & Women & Total & FT worker & PT worker & Unemp. & Inactive \\
\hline Long-term unemployed & 14.2 & 33.6 & 23.4 & 41.7 & 12.8 & 16.7 & 28.9 \\
Intermittently employed & 5.2 & 5.3 & 5.2 & 66.1 & 15.7 & 9.1 & 9.1 \\
Self-employed & 15.7 & 8.1 & 12.2 & 84.0 & 5.0 & 5.0 & 6.0 \\
Professional & 6.8 & 5.4 & 6.1 & 75.4 & 9.2 & 9.2 & 6.3 \\
Public employee & 11.4 & 18.9 & 15.0 & 87.9 & 9.2 & 1.2 & 1.7 \\
Blue-collar worker & 30.9 & 11.1 & 21.5 & 84.7 & 6.2 & 4.8 & 4.2 \\
White-collar worker & 15.8 & 17.6 & 16.7 & 75.1 & 15.8 & 4.4 & 4.7 \\
Total & 52.8 & 47.2 & 100.0 & 71.9 & 10.3 & 7.5 & 10.3 \\
\hline
\end{tabular}

Source: Elaboration of AD-SILC data.

Finally, the occurrence of specific events during the entire employment trajectory (from age 15 up to age 45) of individuals belonging to the various clusters can be considered. Contrary to the idea of a rigid labour market, all clusters are characterized by a substantively high average number of transitions across employment states (see Table A-1 in the Appendix). As expected, those belonging to the intermittent and longterm unemployed clusters are characterized by more frequent transitions, but members of the professional and white-collar worker clusters also experienced, on average, more than 4 transitions between states over the 31-year period. Furthermore, individuals in the cluster of long-term unemployed and intermittently employed spent 21.4 and 22.5 years, respectively, working 26 weeks in a year at most, while among those belonging to the other clusters the number of years with a low number of working weeks does not exceed 6 - this being, however, an alarming signal of the employment trajectories' poor quality.

\subsection{Longitudinal employment trajectories and health}

Estimates of the link between employment trajectories and SRH are shown in Table 2 ('long-term unemployed' is the reference category of the dependent variable), for the full sample (baseline estimates) and for the subsample excluding individuals who declared themselves to be inactive when aged 45 (i.e., in the year of the IT-SILC interview; 238 observations).

Consistent with Hypothesis 1, the results show that those experiencing long-term unemployment or fragmented working careers are characterized by a significantly lower SRH than those belonging to any other cluster. Interestingly, blue-collar workers 
do not report statistically significantly better health than those belonging to the reference category of long-term unemployed, if self-defined inactive individuals are excluded from the sample (their estimated advantage over the long-term unemployed is only weakly statistically significant in the full sample).

Table 2: Association between clusters representing employment trajectories and self-reported health at middle life: Ordered probit estimates

\begin{tabular}{|c|c|c|c|c|c|c|}
\hline & \multicolumn{3}{|c|}{ Baseline } & \multicolumn{3}{|c|}{ Excluding inactives } \\
\hline & Coef. & Std. Err. & $P>z$ & Coef. & Std. Err. & $P>Z$ \\
\hline Women & -0.0882 & 0.0499 & 0.078 & -0.1101 & 0.0528 & 0.037 \\
\hline Single & -0.1859 & 0.0635 & 0.003 & -0.1882 & 0.0655 & 0.004 \\
\hline Separated & 0.0515 & 0.0811 & 0.525 & 0.0368 & 0.0850 & 0.665 \\
\hline \multicolumn{7}{|c|}{ Long-term unemployed (ref.) } \\
\hline Intermittently employed & 0.0398 & 0.1128 & 0.724 & 0.0181 & 0.1212 & 0.881 \\
\hline Self-employed & 0.2447 & 0.0848 & 0.004 & 0.2219 & 0.0914 & 0.015 \\
\hline Professional & 0.3250 & 0.1067 & 0.002 & 0.2738 & 0.1133 & 0.016 \\
\hline Public employee & 0.3665 & 0.0778 & 0.000 & 0.3405 & 0.0840 & 0.000 \\
\hline Blue-collar worker & 0.1234 & 0.0727 & 0.090 & 0.0856 & 0.0787 & 0.277 \\
\hline White-collar worker & 0.3171 & 0.0757 & 0.000 & 0.2858 & 0.0823 & 0.001 \\
\hline Obs. & 2,313 & & & 2,075 & & \\
\hline
\end{tabular}

Note: Year of birth fixed-effects are included among the covariates. 'Married' is the reference category for marital status. Source: Elaboration of AD-SILC data.

To facilitate the comparison across employment trajectories, Table 3 shows the statistical significance and the direction of the Wald pairwise tests on the equality of the estimated coefficients of clusters of the baseline model (the results are unchanged if the sample is restricted to self-defined active workers). Pairwise comparisons confirm that being out of the regular labour force and experiencing job insecurity due to frequent short unemployment spells is associated with statistically significantly worse health. Consistent with Hypothesis 2, among those with a stronger attachment to the labour market, blue-collar workers report significantly worse health than professionals, whitecollar workers, and public sector employees, while no significant differences emerge between blue-collar workers and those experiencing frequent job insecurity.

These results are robust to the inclusion of further controls (e.g., short-term unemployment spells) that, however, contribute to the construction of the employment trajectory (Appendix, Table A-1) or might be endogenous to the 31-year-long observational window considered here (Appendix, Tables A-2 and A-3).

Figure 2 plots the predicted distribution of the 5 categories of SRH for the seven clusters of employment trajectories computed using estimates from the baseline model. The predicted probability of reporting bad or very bad health is $5.0 \%, 4.5 \%$, and $3.8 \%$ among the long-term unemployed, intermittent workers, and blue-collar workers, respectively, whereas these percentages are significantly lower for those belonging to 
the other clusters: $2.9 \%$ (self-employed), $2.5 \%$ (both professionals and white-collar workers), and $2.2 \%$ (public employees).

Table 3: $\quad$ Significance and direction of the Wald test of pairwise comparisons of estimated coefficients between clusters of employment trajectories

\begin{tabular}{|c|c|c|c|c|c|c|c|}
\hline & $\begin{array}{l}\text { Long-term } \\
\text { unemployed }\end{array}$ & $\begin{array}{l}\text { Intermittently } \\
\text { employed }\end{array}$ & Self-employed & Professional & $\begin{array}{l}\text { Public } \\
\text { employee }\end{array}$ & $\begin{array}{c}\text { Blue-collar } \\
\text { worker }\end{array}$ & $\begin{array}{c}\text { White-collar } \\
\text { worker }\end{array}$ \\
\hline \multicolumn{8}{|l|}{ Long-term unemployed } \\
\hline Intermittently employed & n.s. & & & & & & \\
\hline Self-employed & $+* * *$ & $+{ }^{*}$ & & & & & \\
\hline Professional & $+* * *$ & $+* *$ & n.s. & & & & \\
\hline Public employee & $+* * *$ & $+* * \star$ & n.s. & n.s. & & & \\
\hline Blue-collar worker & $+*$ & n.s. & n.s. & $-{ }^{*}$ & $-{ }^{\star \star \star}$ & & \\
\hline White-collar worker & $+* * *$ & $t^{\star \star}$ & n.s. & n.s. & n.s. & $+* *$ & \\
\hline
\end{tabular}

Note: 'n.s.': not statistically significant; '+' and '-' indicate better and worse health respectively for those belonging to the employment trajectory cluster in the row compared to those belonging to the clusters in the columns. Estimates from the baseline model in Table 4. $p<0.10 ;{ }^{* *} p<0.05 ;{ }^{* * *} p<0.01$.

Source: Elaboration of AD-SILC data.

Figure 2: $\quad$ Predicted distribution of self-reported health by cluster of employment trajectory

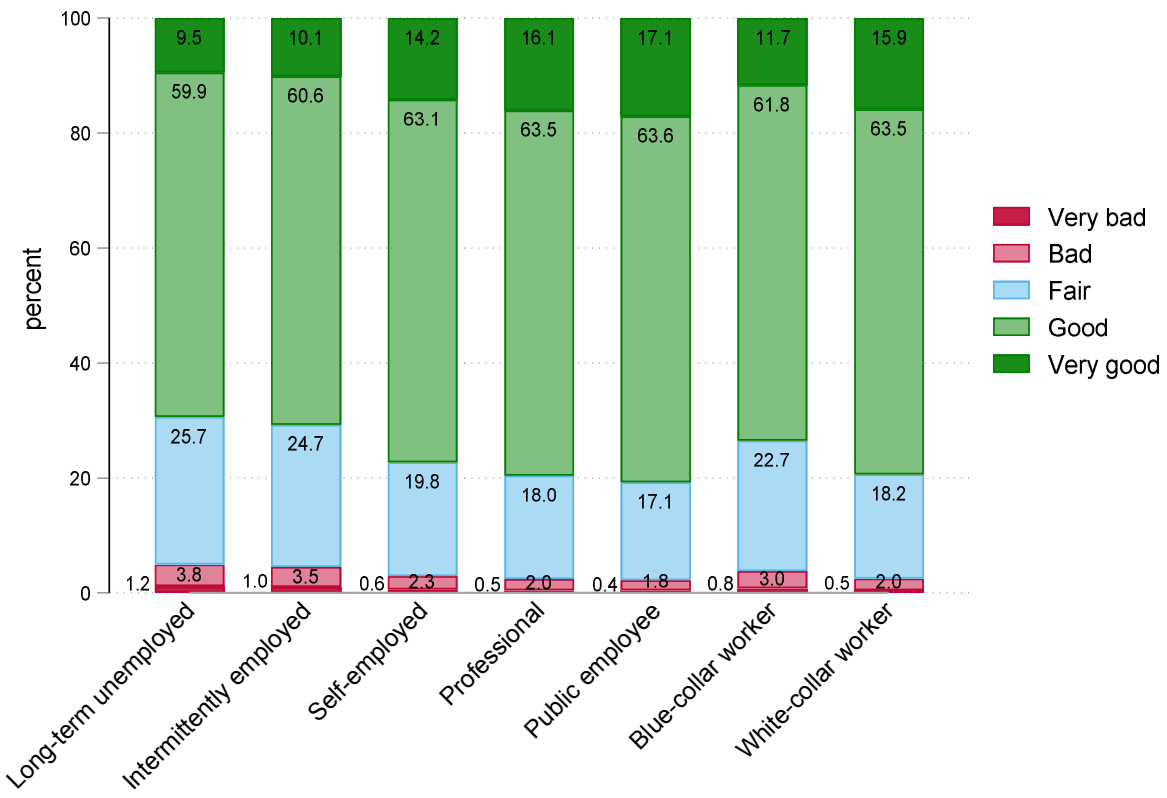

Note: Predicted probabilities from the Baseline Model in Table 2. Source: Elaboration of AD-SILC data. 
As an alternative telling graphical representation, Figure 3 shows the ratio between the predicted probabilities of reporting good or very good health versus bad or very bad health. This ratio is 36.5 for public employees, exceeds 30 for white-collar workers and professionals, and is 26.4 for the self-employed, but declines to 19.3, 15.5, and 14.4 for blue-collar workers, intermittent workers, and the long-term unemployed, respectively. Therefore, the estimated association between life-course employment trajectory and SRH at middle age is large: for instance, for an employee in the public sector the probability of reporting good or very good health instead of bad or very bad health is almost twice the figure for blue-collar workers.

\section{Figure 3: Ratio between the predicted linear probabilities for 'good' or 'very good' health versus 'bad' or 'very bad' health by cluster of employment trajectory}

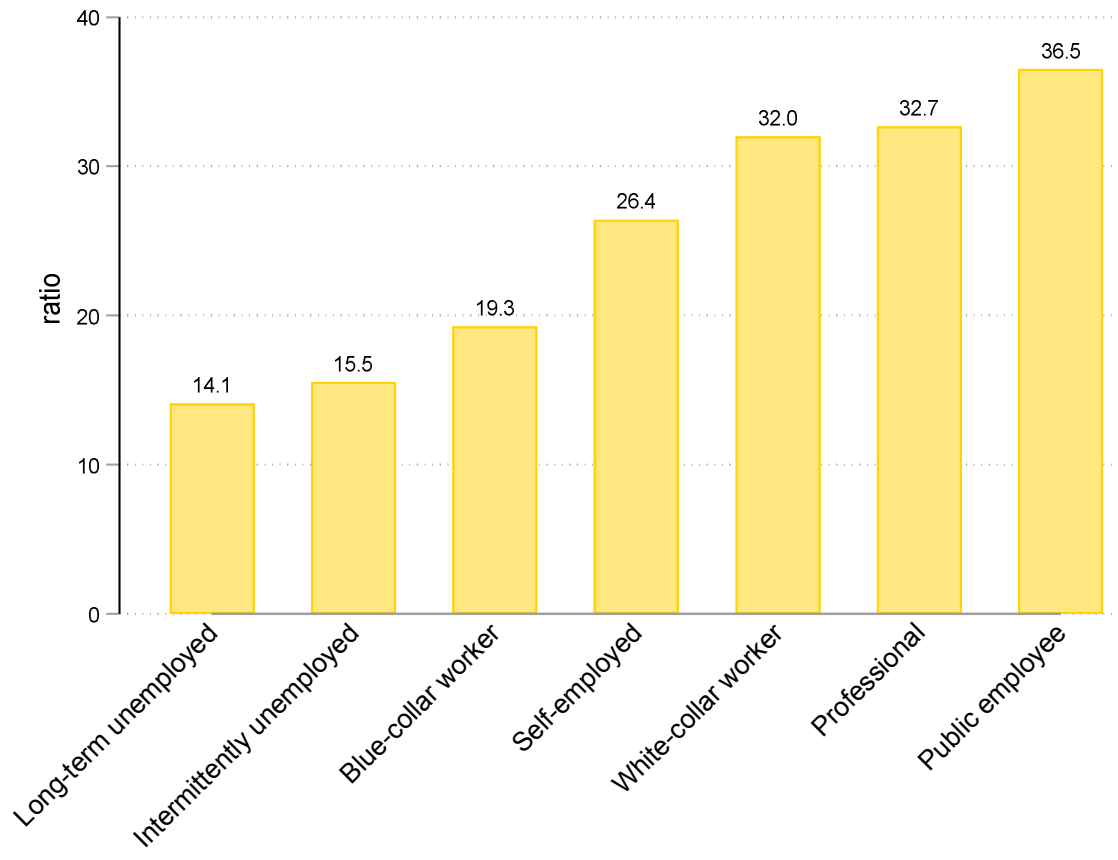

Note: Estimates from the Baseline Model of Table 2.

Source: Elaboration of AD-SILC data. 
The significance of the differences between 'good' or 'very good' health versus 'bad' or 'very bad' health by cluster can be assessed by considering the predicted probabilities for this simplified definition of health outcomes estimated from the baseline model in Table 2. Figure 4 confirms that the relevant differences between the simplified categories as displayed in Figure 3 are significant.

Figure 4: Predicted probabilities for 'good' or 'very good', 'fair', and 'bad' or 'very bad' health by cluster of employment trajectory and $95 \%$ confidence intervals

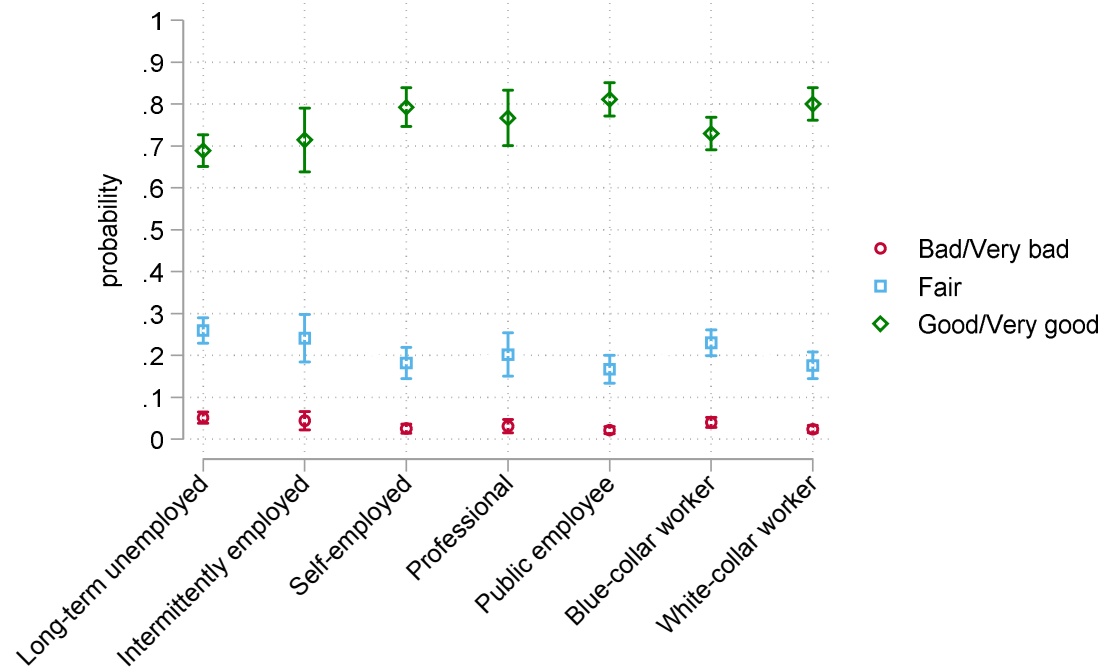

Note: Estimates from the Baseline Model of Table 2.

Source: Elaboration of AD-SILC data.

In order to assess the gains of our analysis relative to the more standard static approach, we replicate Figure 3 using estimates of ordered probit models for SRH where life-course employment trajectories are replaced, at each age, by the 7 grouped categories of employment statuses corresponding to the prevalent statuses characterizing our trajectories (education excluded), or by the original 11 employment statuses. Results displayed in Figures A-4 and A-5 in the Appendix highlight that the predicted probabilities of reporting good or very good health versus bad or very bad health are extremely sensitive to the age at which employment status is recorded and to the aggregation of employment statuses, thus supporting our analytical strategy based on sequences rather than on point-in-time estimates. 


\subsection{Additional remarks on the issue of reverse causality}

A further advantage of using 31-year-long trajectories is that they should reduce the concerns of possible reverse causality between employment and health, which is likely to shape the short-time relationship between labour market events and health status (Baker, Stabile, and Deri 2004). However, although employment careers are measured before the current SRH, estimates can still suffer from self-selection of people into specific employment trajectories. Reassuringly, existing research provides no support for the health selection hypothesis during the life course (Warren 2009). Evidence for Italy confirms that sample health selection into unemployment is negligible (Ardito et al. 2017).

Unfortunately, we cannot directly tackle the issue by controlling for initial health status with our data, because SHR is only recorded once, i.e., at the time of the IT-SILC interview. However, we indirectly control for self-selection into trajectories by excluding from the sample those individuals in the IT-SILC questionnaire who report never having worked. We also show that our results are robust to a different sample selection that excludes individuals who report being inactive at the moment of the ITSILC interview (i.e., at age 45). Note, finally, that the share of individuals reporting bad or very bad health is negligible at the early stages of the life course and increases with age. For example, in the 2012 wave of the IT-SILC survey the share of workers who report suffering from bad or very bad health is $3.4 \%$ in the $40-45$ age bracket and $1.4 \%$ among those aged 20-25. This should reduce the concern that self-selection into employment trajectories is a major driver of the association with SRH at age 45 found in our analysis.

\section{Conclusions}

In this article we address two major limitations of existing literature on labour-market experience and health: We consider a large spectrum of employment statuses to capture the wide range of conditions that characterize contemporary labour markets, and we observe long-run employment trajectories over the life course to understand how health outcomes depend on the length of exposure to a variety of statuses. We therefore advance the existing literature, which relies mainly on the observation of a few employment statuses measured at one or a few points in time. Our analyses make use of sequence analyses tools and ordered probit regression models to estimate the association between individuals' longitudinal employment trajectories and SRH.

By using a unique linked administrative and survey dataset for Italy, we construct 31-year-long employment trajectories, accounting for 11 possible mutually exclusive 
employment statuses. We find a large negative health gradient for experiencing long spells out of the regular labour force or frequent short unemployment spells. We also document large variability in SRH between types of workers, with those spending long periods as blue-collar workers reporting significantly worse health than those engaged in trajectories as professionals, white-collar workers, or public sector employees. Interestingly, these findings suggest that long-term exposure to potentially physically demanding jobs (which are also relatively less paid and allow low levels of individual control) operates similarly to persistent/intermittent joblessness in terms of health outcome.

Some limitations have to be acknowledged. As discussed above, concerns remain regarding the potential (self-)selection of workers into specific employment trajectories. AD-SILC data allowed us to trace the process of labour market participation for an unprecedentedly long observational window and to exclude disabled individuals and individuals that never entered the labour market. Far from being the ideal solution to avoid the risk of reverse causality, our are the only available results on the association between employment trajectories and health at middle life based on a sample of individuals observed over 31 years with no attrition issues. This descriptive evidence can be the starting point for future enquires. Second, the different domains of the life course are intertwined and can jointly affect long-term outcomes. As an example, occurrences in the family life course (e.g., transition to parenthood) can have spillover effects on labour market participation in the short run (mother's temporary exit from the labour force), and this can generate long-term disparities in terms of wages or pensions (persistent motherhood penalty) that affect health. Also in this case, our findings can inform future investigations into the dynamic interplay of employment and family trajectories.

Notwithstanding these limitations, our results suggest more generally that the social cost of individuals' health resulting from unstable/low-quality employment trajectories could be high. This result is of utmost importance as it concerns a country with a universal health care system, which was relatively well financed in Italy in the time frame considered here. We therefore foresee the role of labour-market social security institutions as crucial. Our results suggest that ensuring decent working conditions is of primary importance, over and above guaranteeing access to the labour market and adequate wages. We demonstrated that looking at work histories as they unfold over the life course overcomes the limitations of looking at single points in time and uncovers less obvious relations between length of exposure to specific states and later health outcomes.

These aspects are of increasing interest, given the institutional changes and shifts in demand and supply experienced by many Western industrialized labour markets. The massive growth of non-standard working arrangements, such as fixed-term, on-call, 
temporary, and self-employed subcontracted (Barbieri 2009; Katz and Krueger 2016), has resulted in increasingly complex and volatile employment trajectories that could become principal drivers of poor health outcomes in later life (Quinlan 2015). Our study shows that empirical research will greatly benefit from the growing availability of matched administrative health and labour market data. Exploiting samples with a larger sample size than that used in this article will allow for considering more specific components of individual health that could, for example, be differently associated with the employment trajectories of men and women, and for focusing on mechanisms specific to some sectors of activity and/or low wages. 


\section{References}

Aassve, A., Billari, F.C., and Piccarreta, P. (2007). Strings of adulthood: A sequence analysis of young British women's work-family trajectories. European Journal of Population 23(3-4): 369-388. doi:10.1007/s10680-007-9134-6.

Abbott, A. (1990). A primer on sequence methods. Organization Science 1(4): 375392. doi:10.1287/orsc.1.4.375.

Abbott, A. (1995). Sequence analysis: New methods for old ideas. Annual Review of Sociology 21: 93-113. doi:10.1146/annurev.so.21.080195.000521.

Aisenbrey, S. and Fasang, A.E. (2010). New life for old ideas: The 'second wave' of sequence analysis bringing the 'course' back into the life course. Sociological Methods and Research 38(3): 420-462. doi:10.1177/0049124109357532.

Ardito, C., Leombruni, R., Mosca, M., Giraudo, M., and d'Errico, A. (2017). Scar on my heart: Effects of unemployment experiences on coronary heart disease. International Journal of Manpower 38(1): 62-92. doi:10.1108/IJM-02-20160044 .

Arulampalam, W. (2001). Is unemployment really scarring? Effects of unemployment experiences on wages. The Economic Journal 111(475): 585-606. doi:10.1111/ 1468-0297.00664.

Bago d'Uva, T., Van Doorslaer, E., Lindeboom, M., and O'Donnell, O. (2008). Does reporting heterogeneity bias the measurement of health disparities? Health Economics 17(3): 351-375. doi:10.1002/hec.1269.

Bailis, D.S., Segall, A., and Chipperfield, J.G. (2003). Two views of self-rated general health status. Social Science and Medicine 56(2): 203-217. doi:10.1016/S02779536(02)00020-5.

Baker, M., Stabile, M., and Deri, C. (2004). What do self-reported, objective, measures of health measure? Journal of Human Resources 39(4): 1067-1093. doi: $10.2307 / 3559039$.

Barbieri, P. (2009). Flexible employment and inequality in Europe. European Sociological Review 25(6): 621-628. doi:10.1093/esr/jcp020.

Bardasi, E. and Francesconi, M. (2004). The impact of atypical employment on individual wellbeing: Evidence from a panel of British workers. Social Science and Medicine 58(9): 1671-1688. doi:10.1016/S0277-9536(03)00400-3. 
Baxter, P.J., Aw, T.C., Cockcroft, A., Durringtone, P., and Harrington, J.M. (2010). Hunter's diseases of occupations. London: CRC Press. doi:10.1201/b13467.

Benach, J. and Muntaner, C. (2007). Precarious employment and health: Developing a research agenda. Journal of Epidemiology and Community Health 61(4): 276277. doi:10.1136/jech.2005.045237.

Benach, J. and Muntaner, C. (2013). Employment, work and health inequalities: A global perspective. Barcelona: Icaria Editorial.

Benach, J., Vives, A., Amable, M., Vanroelen, C., Delclos, C., and Muntaner, C. (2016). What should we know about precarious employment and health in 2025 ? Framing the agenda for the next decade of research. International Journal of Epidemiology 45(1): 232-238. doi:10.1093/ije/dyv342.

Benach, J., Vives, A., Amable, M., Vanroelen, C., Tarafa, G., and Muntaner, C. (2014). Precarious employment: Understanding an emerging social determinant of health. Annual Review of Public Health 35(1): 229-253. doi:10.1146/annurevpublhealth-032013-182500.

Bergroth, L., Hakonen, H., and Raita, T. (2000). A survey of longest common subsequence algorithms. In: Proceedings Seventh International Symposium on String Processing and Information Retrieval. Los Alamitos: IEEE: 39-48. doi:10.1109/SPIRE.2000.878178.

Booth, A.L., Francesconi, M., and Frank, J. (2002). Temporary jobs: Stepping stones or dead ends? The Economic Journal 112(480): 189-213. doi:10.1111/14680297.00043 .

Cai, L. (2010). The relationship between health and labour force participation: Evidence from a panel data simultaneous equation model. Labour Economics 17(1): 77-90. doi:10.1016/j.labeco.2009.04.001.

Carrieri, V., Di Novi, C., Jacobs, R., and Robone, S. (2014). Insecure, sick and unhappy? Well-being consequences of temporary employment contracts. In: Polachek, S.W. and Tatsiramos, K. (eds.). Factors affecting worker well-being: The impact of change in the labor market. Bingley: Emerald Group: 157-193. doi:10.1108/S0147-912120140000040006.

Carroll, J.M., Muller, C., Grodsky, E., and Warren, J.R. (2017). Tracking health inequalities from high school to midlife. Social Forces 96(2): 591-628. doi:10.1093/sf/sox065. 
Cockx, B. and Picchio, M. (2012). Are short-lived jobs stepping stones to long-lasting jobs? Oxford Bulletin of Economics and Statistics 74(5): 646-675. doi:10.1111/j.1468-0084.2011.00668.x.

Costa, G., Sartori, S., and Åkerstedt, T. (2006). Influence of flexibility and variability of working hours on health and well-being. Chronobiology International 23(6): 1125-1137. doi:10.1080/07420520601087491.

Cottini, E. and Lucifora, C. (2013). Mental health and working conditions in Europe. Industrial and Labour Relations Review 66(4): 958-988. doi:10.1177/ 001979391306600409.

Drydakis, N. (2015). The effect of unemployment on self-reported health and mental health in Greece from 2008 to 2013: A longitudinal study before and during the financial crisis. Social Science and Medicine 128: 43-51. doi:10.1016/ j.socscimed.2014.12.025.

Ehlert, C. and Schaffner, S. (2011). Health effects of temporary jobs in Europe. Bochum: Ruhr-Universität Bochum, Department of Economics (Ruhr Economic Papers 295). doi:10.2139/ssrn.1969770.

Elzinga, C.H. and Liefbroer, A.C. (2007). De-standardization of family-life trajectories of young adults: A cross-national comparison using sequence analysis. European Journal of Population 23(3): 225-250. doi:10.1007/s10680-007-91337.

Fagan, P., Shavers, V., Lawrence, D., Gibson, J.T., and Ponder, P. (2007). Cigarette smoking and quitting behaviours among unemployed adults in the United States. Nicotine and Tobacco Research 9(2): 241-248. doi:10.1080/ 14622200601080331 .

Farré, L., Fasani, F., and Mueller, H.F. (2018). Feeling useless: The effect of unemployment on mental health in the Great Recession. IZA Journal of Labor Economics 7(8): 1-34. doi:10.1186/s40172-018-0068-5.

Fasang, A.E. and Liao, T.F. (2014). Visualizing sequences in the social sciences: Relative frequency sequence plots. Sociological Methods and Research 43(4): 643-676. doi:10.1177/0049124113506563.

Ferrie, J.E., Shipley, M.J., Newman, K., Stansfeld, S.A., and Marmot, M. (2005). Selfreported job insecurity and health in the Whitehall II study: Potential explanations of the relationship. Social Science and Medicine 60(7): 1593-1602. doi:10.1016/j.socscimed.2004.08.006. 
Friel, S. and Marmot, M. (2011). Action on the social determinants of health and health inequities goes global. Annual Review of Public Health 32(1): 225-236. doi:10.1146/annurev-publhealth-031210-101220.

Gabadinho, A., Ritschard, G., Müller, N.S., and Studer, M. (2011). Analyzing and visualizing state sequences in $\mathrm{R}$ with TraMineR. Journal of Statistical Software 40(4): 1-37. doi:10.18637/jss.v040.i04.

Gangl, M. (2004). Welfare states and the scar effects of unemployment: A comparative analysis of the United States and West Germany. American Journal of Sociology 109(6): 1319-1364. doi:10.1086/381902.

Gash, V. and McGinnity, F. (2006). Fixed-term contracts: The new European inequality? Comparing men and women in West Germany and France. SocioEconomic Review 5(3): 467-496. doi:10.1093/ser/mwl020.

Godin, I. and Kittel, F. (2004). Differential economic stability and psychosocial stress at work: Associations with psychosomatic complaints and absenteeism. Social Science and Medicine 58(8): 1543-1553. doi:10.1016/S0277-9536(03)00345-9.

Grayson, J.P. (1993). Health, physical activity level, and employment status in Canada. International Journal of Health Services 23(4): 743-761. doi:10.2190/W5NRA7A4-BX4A-T4F7.

Gregg, P. and Tominey, E. (2005). The wage scar from male youth unemployment. Labour Economics 12(4): 487-509. doi:10.1016/j.labeco.2005.05.004.

Griep, Y., Kinnunen, U., Nätti, J., De Cuyper, N., Mauno, S., Mäkikangas, A., and De Witte, H. (2016). The effects of unemployment and perceived job insecurity: A comparison of their association with psychological and somatic complaints, selfrated health and life satisfaction. International Archives of Occupational and Environmental Health 89(1): 147-162. doi:10.1007/s00420-015-1059-5.

Huber, M., Lechner, M., and Wunsch, C. (2011). Does leaving welfare improve health? Evidence for Germany. Health Economics 20(4): 484-504. doi:10.1002/hec. 1615.

Jahoda, M. (1982). Employment and unemployment: A social-psychological analysis. London: Cambridge University Press.

Jylhä, M. (2009). What is self-rated health and why does it predict mortality? Towards a unified conceptual model. Social Science and Medicine 69(3): 307-316. doi:10.1016/j.socscimed.2009.05.013. 
Katz, L.F. and Krueger, A.B. (2016). The rise and nature of alternative work arrangements in the United States, 1995-2015. Cambridge: National Bureau of Economic Research (NBER Working Paper Series 22667). doi:10.3386/w22667.

Kaufman, L. and Rousseeuw, P.J. (2008). Finding groups in data: An introduction to cluster analysis. New York: Wiley. doi:10.1002/9780470316801.

Kim, I.H., Muntaner, C., Shahidi, F.V., Vives, A., Vanroelen, C., and Benach, J. (2012). Welfare states, flexible employment, and health: A critical review. Health Policy 104(2): 99-127. doi:10.1016/j.healthpol.2011.11.002.

Laitinen, J., Ek, E., and Sovio, U. (2002). Stress-related eating and drinking behavior and body mass index and predictors of this behavior. Preventive Medicine 34(1): 29-39. doi:10.1006/pmed.2001.0948.

László, K.D., Pikhart, H., Kopp, M.S., Bobak, M., Pajak, A., Malyutina, S., Salavecz, G., and Marmot, M. (2010). Job insecurity and health: A study of 16 European countries. Social Science and Medicine 70(6): 867-874. doi:10.1016/j. socscimed.2009.11.022.

Lewchuk, C.M., Clarke, M., and de Wolff, A. (2011). Working without commitments: The health effects of precarious employment. Montreal and Kingston: McGillQueen's University Press.

Mariani, E., Özcan, B., and Goisis, A. (2017). Family trajectories and well-being of children born to lone mothers in the UK. European Journal of Population 33(2): 185-215. doi:10.1007/s10680-017-9420-x.

Marmot, M. (2015). The health gap: The challenge of an unequal world. London: Bloomsbury.

Michaud, P.C., Crimmins, E.M., and Hurd, M.D. (2016). The effect of job loss on health: Evidence from biomarkers. Labour Economics 41: 194-203. doi:10. 1016/j.labeco.2016.05.014.

Mirowsky, J. and Ross, C.E. (2007). Creative work and health. Journal of Health and Social Behavior 48(4): 385-403. doi:10.1177/002214650704800404.

Moore, D.E. and Hayward, M.D. (1990). Occupational careers and mortality of elderly men. Demography 27(1): 31-53. doi:10.2307/2061551.

Moscone, F., Tosetti, E., and Vittadini, G. (2016). The impact of precarious employment on mental health: The case of Italy. Social Science and Medicine 158: 86-95. doi:10.1016/j.socscimed.2016.03.008. 
Mossakowski, K.N. (2008). Is the duration of poverty and unemployment a risk factor for heavy drinking? Social Science and Medicine 67(6): 947-955. doi:10.1016/ j.socscimed.2008.05.019.

Mussida, C. and Lucarelli, C. (2014). Dynamics and performance of the Italian labour market. Economia Politica 31(1): 33-54.

Pirani, E. (2017). On the relationship between atypical work(s) and mental health: New insights from the Italian case. Social Indicators Research 130(1): 233-252. doi:10.1007/s11205-015-1173-5.

Pirani, E. and Salvini, S. (2015). Is temporary employment damaging to health? A longitudinal study on Italian workers. Social Science and Medicine 124: 121131. doi:10.1016/j.socscimed.2014.11.033.

Quesnel-Vallée, A., DeHaney, S., and Ciampi, A. (2010). Temporary work and depressive symptoms: A propensity score analysis. Social Science and Medicine 70(12): 1982-1987. doi:10.1016/j.socscimed.2010.02.008.

Quinlan, M. (2015). The effects of non-standard forms of employment on worker health and safety. Geneva: International Labour Office (Conditions of Work and Employment Series No. 67).

Quinlan, M. and Bohle, P. (2004). Contingent work and occupational safety. In: Barlin, J. and Frone, M.R. (eds.). The psychology of workplace safety. Washington, D.C.: American Psychological Association: 81-105. doi:10.1037/10662-005.

R Core Team (2016). R: A language and environment for statistical computing [electronic resource]. Vienna: $\mathrm{R}$ Foundation for Statistical Computing. http://www.R-project.org.

Ringback Weitoft, G. and Rosén, M. (2005). Is perceived nervousness and anxiety a predictor of premature mortality and severe morbidity? A longitudinal follow up of the Swedish survey of living conditions. Journal of Epidemiology and Community Health 59(9): 794-798. doi:10.1136/jech.2005.033076.

Ritschard, G., Bürgin, R., Studer, M., and Müller, N.S. (2013). TraMineRextras: Extras for use with the TraMineR package [electronic resource]. Geneva: CRAN. https://cran.r-project.org/web/packages/TraMineRextras/index.html.

Robone, S., Jones, A.M., and Rice, N. (2011). Contractual conditions, working conditions and their impact on health and well-being. The European Journal of Health Economics 12(5): 429-444. doi:10.1007/s10198-010-0256-0. 
Rodriguez, E. (2002). Marginal employment and health in Britain and Germany: Does unstable employment predict health? Social Science and Medicine 55(6): 963979. doi:10.1016/S0277-9536(01)00234-9.

Ross, C.E. and Wu, C. (1995). The links between education and health. American Sociological Review 60(5): 719-745. doi:10.2307/2096319.

Sarti, S. and Zella, S. (2016). Changes in the labour market and health inequalities during the years of the recent economic downturn in Italy. Social Science Research 57: 116-132. doi:10.1016/j.ssresearch.2015.12.010.

Schaller, J. and Huff Stevens, A. (2015). Short-run effects of job loss on health conditions, health insurance, and health care utilization. Journal of Health Economics 43: 190-203. doi:10.1016/j.jhealeco.2015.07.003.

Schunck, R. and Rogge, B.G. (2010). Unemployment and its association with healthrelevant actions: Investigating the role of time perspective with German census data. International Journal of Public Health 55(4): 271-278. doi:10.1007/ s00038-009-0075-1.

Scott-Marshall, H. and Tompa, E. (2011). The health consequences of precarious employment experiences. Work 38(4): 369-382. doi:10.3233/WOR-2011-1140.

Sen, A. (2002). Health: Perception versus observation. BMJ 324(7342): 860-861. doi:10.1136/bmj.324.7342.860.

Silla, I., Gracia, F.J., and Peiró, J.M. (2005). Job insecurity and health-related outcomes among different types of temporary workers. Economic and Industrial Democracy 26(1): 89-117. doi:10.1177/0143831X05049404.

Strandh, M., Winefield, A., Nilsson, K., and Hammarström, A. (2014). Unemployment and mental health scarring during the life course. The European Journal of Public Health 24(3): 440-445. doi:10.1093/eurpub/cku005.

Stringhini, S., Carmeli, C., Jokela, M., Avendaño, M., Muennig, P., Guida, F., Ricceri, F., d'Errico, A., Barros, H., Bochud, M., Chadaeu-Hyam, M., Clacel-Chapelon, F., Costa, G., Delphierre, C., Fraga, S., Goldberg, M., Giles, G.G., Krogh, V., Kelly-Irving, M., Layte, R., Lasserre, A.M., Marmot, M., Preisig, M., Shipley, M.J., Vollenweider, P., Zins, M., Kawachi, I., Steptoe, A., Mackenbach, J.P., Vineis, P., and Kivimäki, M. (2017). Socioeconomic status and the $25 \times 25$ risk factors as determinants of premature mortality: A multicohort study and metaanalysis of 1.7 million men and women. The Lancet 389(10075): 1229-1237. doi:10.1016/S0140-6736(16)32380-7. 
Strully, K.W. (2009). Job loss and health in the US labour market. Demography 46(2): 221-246. doi:10.1353/dem.0.0050.

Studer, M. and Ritschard, G. (2016). What matters in differences between life trajectories: A comparative review of sequence dissimilarity measures. Journal of the Royal Statistical Society Series A: Statistics in Society 179(2): 481-511. doi:10.1111/rssa.12125.

Sullivan, D. and Von Wachter, T. (2009). Job displacement and mortality: An analysis using administrative data. The Quarterly Journal of Economics 124(3): 12651306. doi:10.1162/qjec.2009.124.3.1265.

Tapia Granados, J.A., House, J.S., Ionides, E.L., Burgard, S., and Schoeni, R.S. (2014). Individual joblessness, contextual unemployment, and mortality risk. American Journal of Epidemiology 180(3): 280-287. doi:10.1093/aje/kwu128.

Tompson, W. (2009). The political economy of reform: Lessons from pensions, product markets and labour markets in ten OECD countries. Paris: OECD. doi:10.1787/ 9789264073111-en.

Van Aerden, K., Puig-Barrachina, V., Bosmans, K., and Vanroelen, C. (2016). How does employment quality relate to health and job satisfaction in Europe? A typological approach. Social Science and Medicine 158: 132-140. doi:10.1016/ j.socscimed.2016.04.017.

Virtanen, M., Kivimäki, M., Joensuu, M., Virtaten, P., Elovainio, M., and Vahtera, J. (2004). Temporary employment and health: A review. International Journal of Epidemiology 34(3): 610-622. doi:10.1093/ije/dyi024.

Virtanen, P., Vahtera, J., Kivimäki, M., Liukkonen, V., Virtanen, V., and Ferrie, J.F. (2005). Labour market trajectories and health: A four-year follow-up study of initially fixed-term employees. American Journal of Epidemiology 161(9): 840846. doi:10.1093/aje/kwi107.

Vives, A., González, F., Moncada, S., Llorens, C., and Benach, J. (2015). Measuring precarious employment in times of crisis: The revised Employment Precariousness Scale (EPRES) in Spain. Gaceta Sanitaria 29(5): 379-382. doi:10.1016/j.gaceta.2015.06.008.

Waenerlund, A.K., Gustafsson, P.E., Hammarström, A., and Virtanen, P. (2014). History of labour market attachment as a determinant of health status: A 12-year follow-up of the Northern Swedish cohort. BMJ Open 4(2): e004053. doi:10.1136/bmjopen-2013-004053. 
Devillanova, Raitano \& Struffolino: Longitudinal employment trajectories and health in middle life

Warren, J.R. (2009). Socioeconomic status and health across the life course: A test of the social causation and health selection hypotheses. Social Forces 87(4): 21252153. doi:10.1353/sof.0.0219.

Williams, R. (2006). Generalized ordered logit/partial proportional odds models for ordinal dependent variables. The Stata Journal 6(1): 58-82. doi:10.1177/ 1536867 X0600600104. 


\section{Appendix}

\section{Figure A-1: Distribution of employment statuses at age 45}

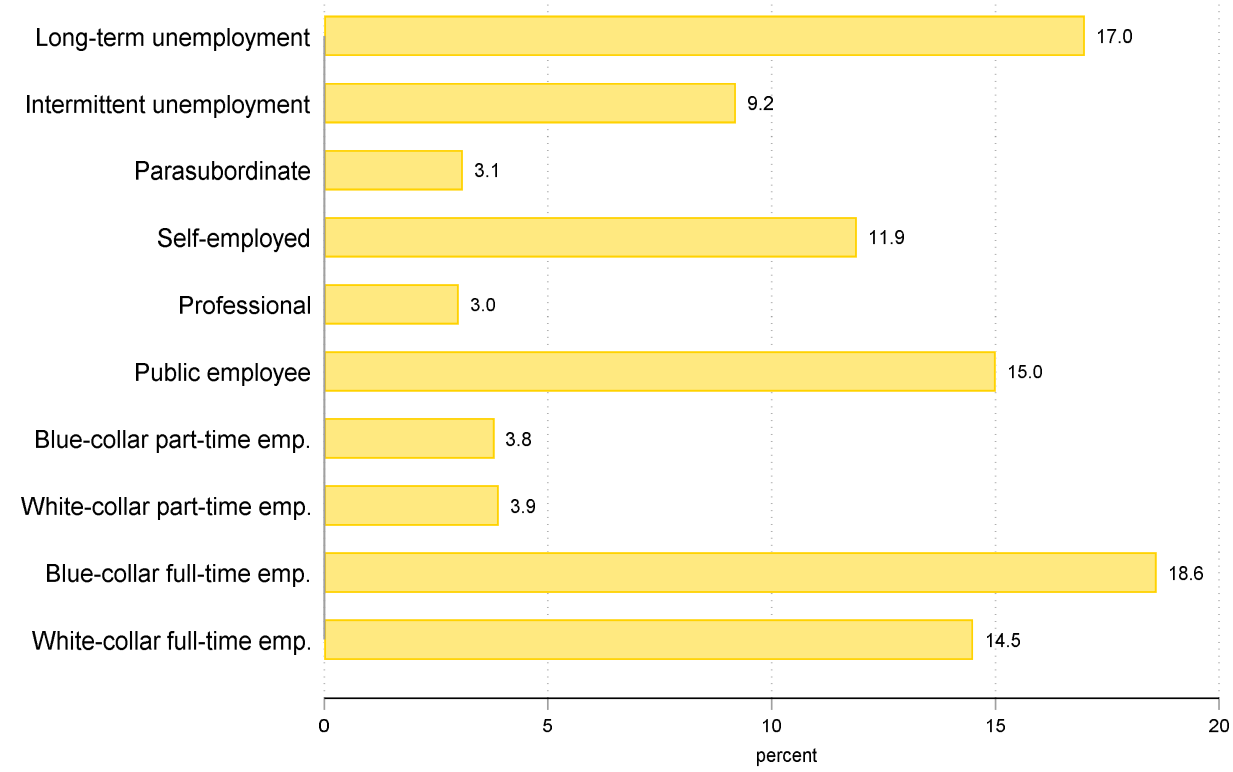

Source: Elaboration of AD-SILC data. 


\section{Figure A-2: Dissimilarities to the medoid within each frequency group as a box- and-whisker plot by cluster}
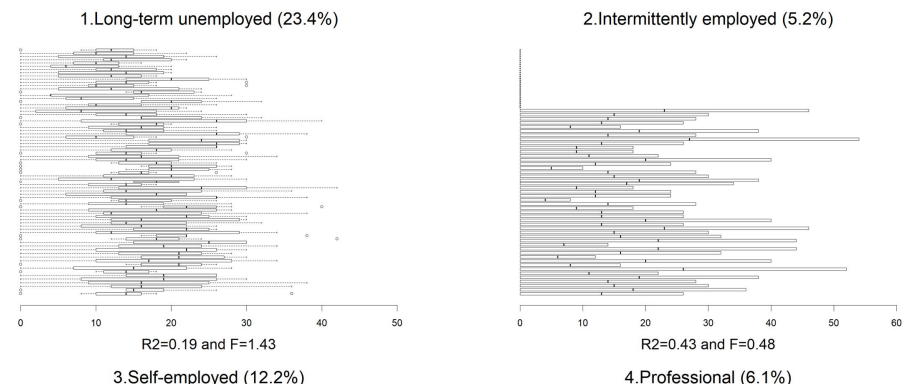

3.Self-employed (12.2\%)
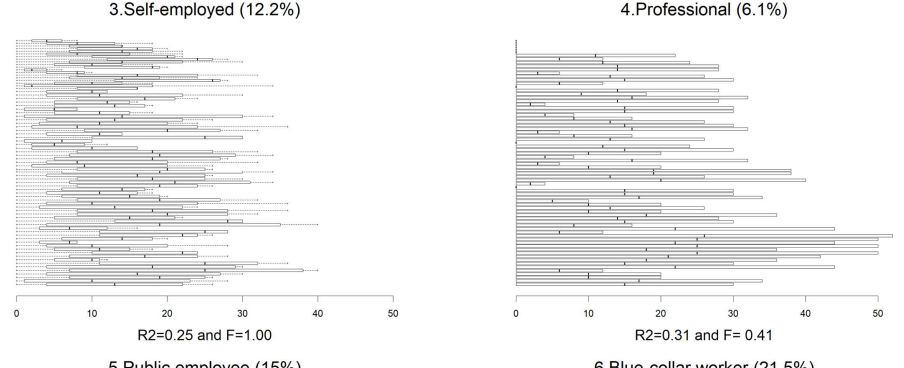

6.Blue-collar worker $(21.5 \%)$
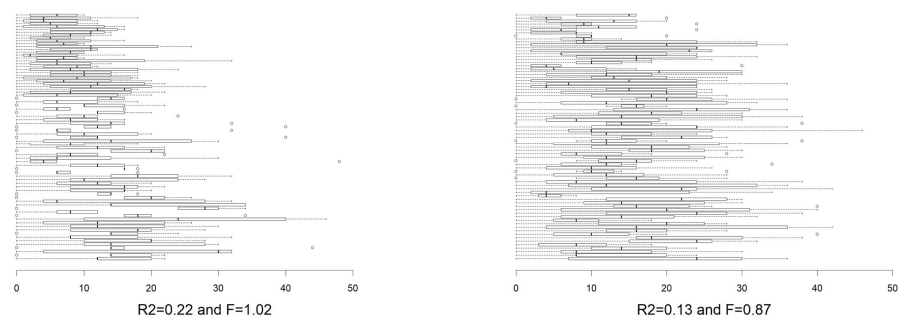

7.White-collar worker (16.7\%)

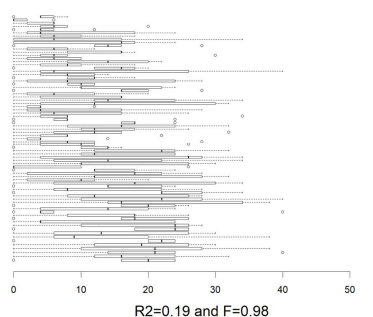

Note: Y-axis reports the box-and-whisker plot for dissimilarities to the medoid within each frequency group; X-axis displays distance from the medoid selected as the most suitable representative sequence of each frequency group. R2 and F statistics for the goodness of fit are displayed below each plot.

Source: Elaboration of AD-SILC data. 


\section{Figure A-3: State distribution plots for the clusters of employment trajectories}
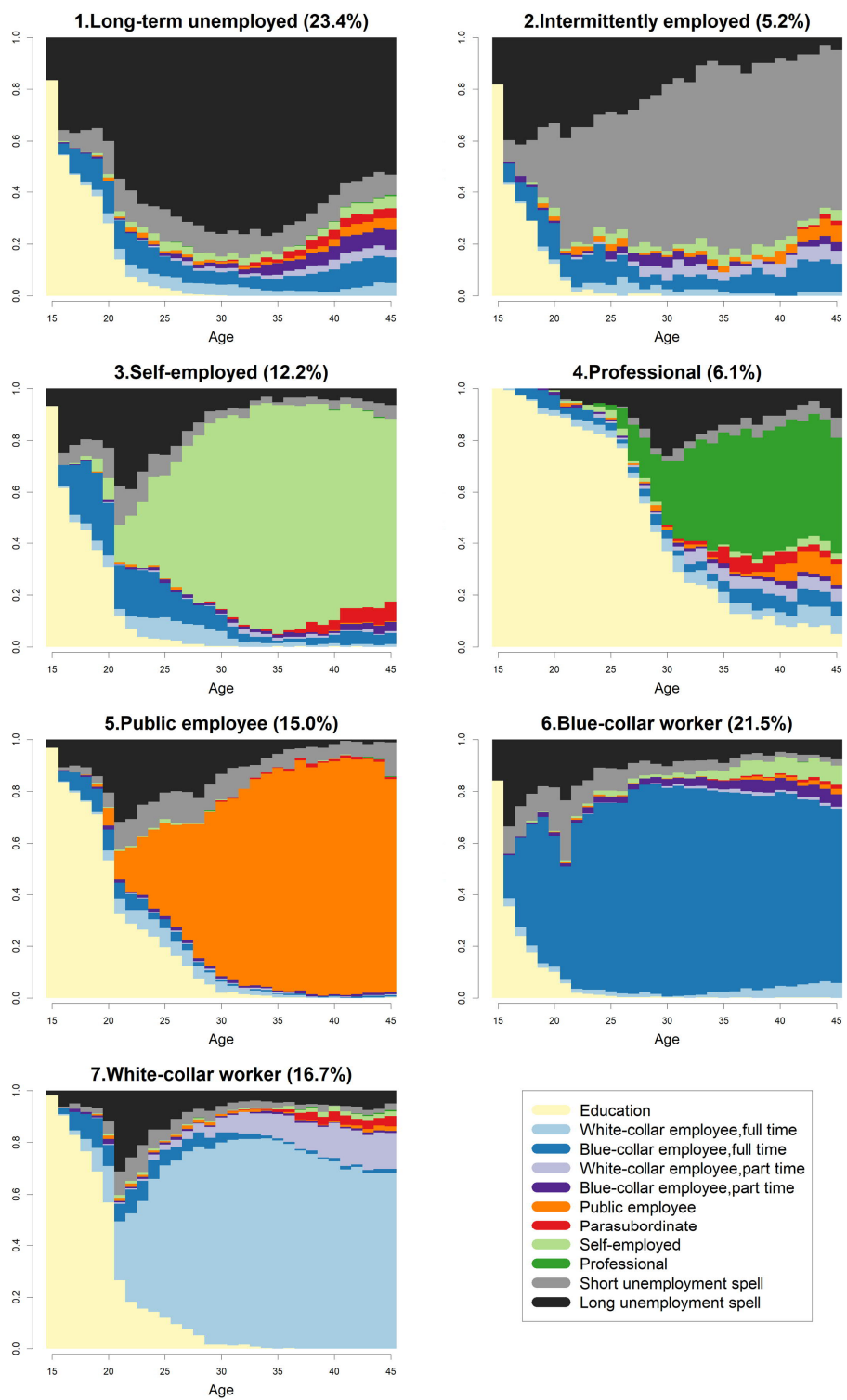

Note: Y-axis reports the share of individuals assigned to each cluster being in a specific labour market status at each time point (which is age as displayed on the $X$-axis).

Source: Elaboration of AD-SILC data. 
Figure A-4: Ratio between the predicted probabilities of 'good' or 'very good' health versus 'bad' or 'very bad' health at each age for each state identified as prevalent in employment trajectory clusters
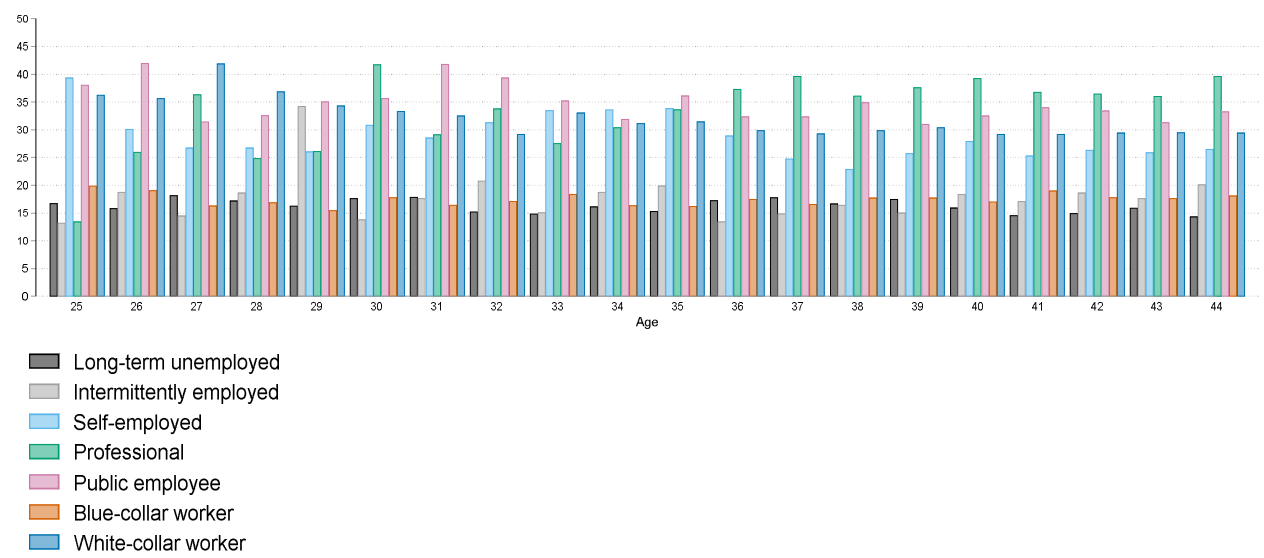

Source: Elaboration of AD-SILC data.

Figure A-5: Ratio between the predicted probabilities of 'good' or 'very good' health versus 'bad' or 'very bad' health at each age for each state used to construct the employment trajectory (education excluded)

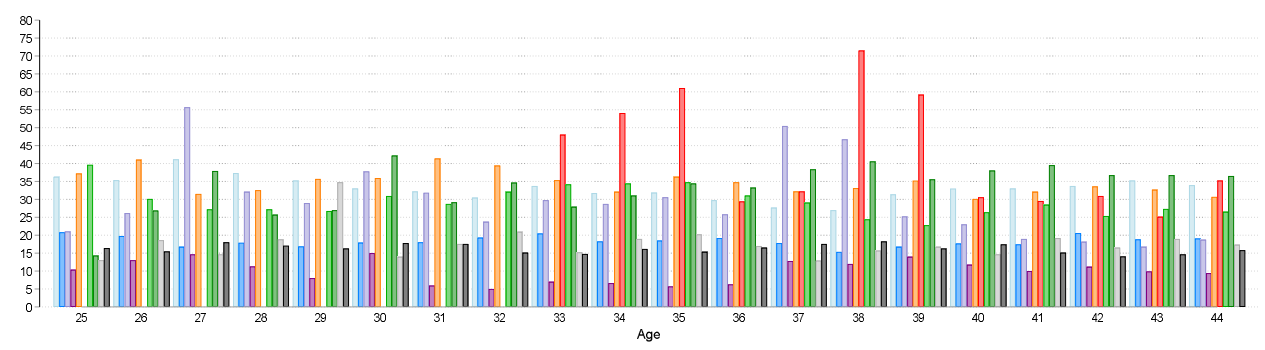

White-collar employee, full-time

$\square$ Blue-collar employee, full-time

$\square$ White-collar employee, part-time

$\square$ Blue-collar employee, part-time

$\square$ Public employee

$\square$ Parasubordinate

$\square$ Self-employed

$\square$ Professional

$\square$ Short unemployment spell

$\square$ Long unemployment spell

Source: Elaboration of AD-SILC data. 
Table A-1: Average number of transitions between employment statuses and average number of years spent in unemployment by cluster (standard variation in brackets)

\begin{tabular}{lcccc}
\hline Cluster & $\begin{array}{c}\text { Total } \\
\text { nr. transitions }\end{array}$ & $\begin{array}{c}\text { Transitions toward } \\
\text { long-term } \\
\text { unemployment }\end{array}$ & $\begin{array}{c}\text { Transitions toward } \\
\text { short-term } \\
\text { unemployment }\end{array}$ & $\begin{array}{c}\text { Years spent in } \\
\text { unemployment }\end{array}$ \\
\hline Long-term unemployed & 6.5 & 2.5 & 1.9 & 21.4 \\
Intermittently employed & $(3.5)$ & $(1.4)$ & $(1.5)$ & $(5.4)$ \\
Self-employed & 6.7 & 1.9 & 2.7 & 22.5 \\
Professional & $(3.9)$ & $(1.4)$ & $(1.6)$ & $(6.4)$ \\
Public employee & 5.3 & 1.3 & 1.1 & 5.8 \\
Blue-collar worker & $(3.0)$ & $(1.1)$ & $(1.1)$ & $(4.6)$ \\
White-collar worker & 4.1 & 0.9 & 0.5 & 3.8 \\
& $(2.6)$ & $(0.8)$ & $(0.8)$ & $(4.2)$ \\
Total & 5.1 & 1.1 & 1.4 & 5.8 \\
& $(2.7)$ & $(1.0)$ & $(1.1)$ & $(4.7)$ \\
& 5.7 & 1.3 & 1.4 & 5.5 \\
& $(3.2)$ & $(1.2)$ & $(1.3)$ & $(4.6)$ \\
& 4.6 & 1.1 & 0.8 & 3.7 \\
& $(2.8)$ & $(1.0)$ & $(0.9)$ & $(3.7)$ \\
\hline
\end{tabular}

Source: Elaboration of AD-SILC data. 
Devillanova, Raitano \& Struffolino: Longitudinal employment trajectories and health in middle life

Table A-2: Association between clusters of employment trajectories and selfreported health. Robustness checks including indicators for the prevalence of different transitions and permanence in unemployment along individual sequences as covariates: ordered probit estimates

\begin{tabular}{|c|c|c|c|c|c|}
\hline & R1 & $\mathbf{R 2}$ & R3 & R4 & R5 \\
\hline \multicolumn{6}{|l|}{ Long-term unemployed (ref.) } \\
\hline \multirow[t]{2}{*}{ Intermittently employed } & 0.0565 & 0.0424 & 0.0273 & 0.0529 & 0.0462 \\
\hline & {$[0.1130]$} & {$[0.1128]$} & [0.1133] & {$[0.1136]$} & {$[0.1130]$} \\
\hline \multirow[t]{2}{*}{ Self-employed } & $0.2180^{\star \star}$ & $0.2338^{\star \star \star}$ & $0.2172^{\star \star}$ & $0.2304^{\star \star \star}$ & 0.1679 \\
\hline & {$[0.0852]$} & {$[0.0852]$} & {$[0.0883]$} & {$[0.0861]$} & {$[0.1136]$} \\
\hline \multirow[t]{2}{*}{ Professional } & 0.0624 & $0.3013^{\star \star \star}$ & $0.2882^{\star \star *}$ & $0.2989^{\star \star \star}$ & $0.2375^{*}$ \\
\hline & [0.1202] & {$[0.1082]$} & {$[0.1116]$} & {$[0.1101]$} & {$[0.1370]$} \\
\hline \multirow[t]{2}{*}{ Public employee } & $0.2336^{\star \star \star}$ & $0.3527^{\star \star \star}$ & $0.3356^{\star \star *}$ & $0.3561^{\star \star \star}$ & $0.2890^{\star \star *}$ \\
\hline & {$[0.0817]$} & {$[0.0785]$} & {$[0.0826]$} & {$[0.0786]$} & [0.1089] \\
\hline \multirow[t]{2}{*}{ Blue-collar worker } & $0.1637^{\star \star}$ & 0.1159 & 0.0969 & 0.1134 & 0.0455 \\
\hline & {$[0.0734]$} & [0.0729] & {$[0.0765]$} & {$[0.0735]$} & {$[0.1057]$} \\
\hline \multirow[t]{2}{*}{ White-collar worker } & $0.1966^{\star \star}$ & $0.2990^{\star \star \star}$ & $0.2845^{\text {***}}$ & $0.2963^{\star \star *}$ & $0.2293^{\star *}$ \\
\hline & [0.0795] & [0.0769] & {$[0.0811]$} & {$[0.0788]$} & {$[0.1148]$} \\
\hline \multicolumn{6}{|l|}{ Education (ref. Lower secondary) } \\
\hline \multirow[t]{2}{*}{ Upper secondary } & $0.1892^{\star \star \star}$ & & & & \\
\hline & {$[0.0547]$} & & & & \\
\hline \multirow[t]{2}{*}{ Tertiary } & $0.4733^{\star * *}$ & & & & \\
\hline & {$[0.0907]$} & & & & \\
\hline \multirow[t]{2}{*}{ Total transitions } & & -0.0099 & & & \\
\hline & & [0.0075] & & & \\
\hline \multirow[t]{2}{*}{ Transitions toward long-term unemp. } & & & -0.0224 & & \\
\hline & & & {$[0.0200]$} & & \\
\hline \multirow[t]{2}{*}{ Transitions toward short unemp. spells } & & & & -0.0179 & \\
\hline & & & & {$[0.0187]$} & \\
\hline \multirow[t]{2}{*}{ Years with unemp. spells } & & & & & -0.005 \\
\hline & & & & & {$[0.0049]$} \\
\hline Obs. & 2,313 & 2,313 & 2,313 & 2,313 & 2,313 \\
\hline
\end{tabular}

Note: Year of birth fixed-effects are included as covariate in all specifications. Standard errors in brackets. ${ }^{*} p<0.10 ;{ }^{* *} p<0.05 ;{ }^{* * *}$ $\mathrm{p}<0.01$.

Source: Elaboration of AD-SILC data. 
Table A-3: Association between clusters of employment trajectories and selfreported health. Robustness checks including socioeconomic indicators among covariates: ordered probit estimates

\begin{tabular}{|c|c|c|c|c|}
\hline & $\mathbf{R 6}$ & R7 & R8 & R9 \\
\hline \multicolumn{5}{|l|}{ Long-term unemployed (ref.) } \\
\hline \multirow[t]{2}{*}{ Intermittently employed } & 0.0221 & 0.0375 & 0.0106 & 0.0022 \\
\hline & {$[0.1130]$} & [0.1128] & {$[0.1131]$} & [0.1132] \\
\hline \multirow[t]{2}{*}{ Self-employed } & $0.2037^{\star *}$ & $0.2467^{* * *}$ & $0.1651^{*}$ & $0.1614^{*}$ \\
\hline & {$[0.0854]$} & {$[0.0848]$} & [0.0859] & [0.0862] \\
\hline \multirow[t]{2}{*}{ Professional } & $0.2700^{\star *}$ & $0.3345^{\star \star \star}$ & $0.2486^{\star \star}$ & $0.2190^{\star \star}$ \\
\hline & {$[0.1076]$} & {$[0.1068]$} & {$[0.1076]$} & {$[0.1085]$} \\
\hline \multirow[t]{2}{*}{ Public employee } & $0.3045^{\star * *}$ & $0.3724^{* * *}$ & $0.2881^{* \star *}$ & $0.2853^{* \star *}$ \\
\hline & {$[0.0793]$} & {$[0.0779]$} & {$[0.0790]$} & {$[0.0793]$} \\
\hline \multirow[t]{2}{*}{ Blue-collar worker } & 0.0850 & $0.1251^{*}$ & 0.0921 & 0.0924 \\
\hline & [0.0733] & {$[0.0727]$} & {$[0.0730]$} & {$[0.0730]$} \\
\hline \multirow[t]{2}{*}{ White-collar worker } & $0.2459^{* * *}$ & $0.3166^{* * *}$ & $0.2229^{\star \star *}$ & $0.2144^{\star * *}$ \\
\hline & {$[0.0777]$} & {$[0.0757]$} & {$[0.0774]$} & {$[0.0780]$} \\
\hline \multirow[t]{2}{*}{ Eq. disp. Income } & $0.0991^{\star \star *}$ & & & \\
\hline & {$[0.0237]$} & & & \\
\hline \multirow[t]{2}{*}{ Other hous. memb. eq. disp. inc. } & & $0.0117^{*}$ & & \\
\hline & & {$[0.0064]$} & & \\
\hline \multirow[t]{2}{*}{ Face unexp. exp. } & & & $0.3393^{\star \star \star}$ & \\
\hline & & & {$[0.0563]$} & \\
\hline \multirow[t]{2}{*}{ Make ends meet } & & & & $0.1241^{\star \star \star}$ \\
\hline & & & & {$[0.0224]$} \\
\hline Obs. & 2,313 & 2,313 & 2,313 & 2,313 \\
\hline
\end{tabular}

Note: Year of birth fixed-effects are included among the covariates in all specifications. Income variables are taken in logs. Standard errors in brackets. * $p<0.10$; ${ }^{* *} p<0.05 ;{ }^{* * \star} p<0.01$.

Source: Elaboration of AD-SILC data. 
Devillanova, Raitano \& Struffolino: Longitudinal employment trajectories and health in middle life 